\title{
Analysis of Indole Compounds Quantity in Biomass of Edible Basidiomycota Species from in Vitro Cultures and from Cultures Supplemented with L-Tryptophan
}

\section{B. MUSZYŃSKA ${ }^{1,}{ }^{*}$, K. SUŁKOWSKA-ZIAJA ${ }^{1}$, A. MAŚLANKA ${ }^{2}$, J. ROJOWSKI ${ }^{2}$, W. OPOKA ${ }^{2}$, AND M. LOJEWSKI ${ }^{1}$}

${ }^{1}$ Department of Pharmaceutical Botany, Jagiellonian University, Collegium Medicum, ul. Medyczna 9, Kraków 30-688, Poland

${ }^{2}$ Department of Inorganic and Analytical Chemistry, Jagiellonian University, Collegium Medicum, ul. Medyczna 9, 30-688 Kraków, Poland

*E-mail: muchon@poczta.fm

Summary. The analysis demonstrated that biomass of Agaricus bisporus, Boletus badius, and Cantharellus cibarius contains non-hallucinogenic indole compounds. Addition of L-tryptophan to the in vitro cultures raised the total content of indole compounds. L-Tryptophan became metabolized, causing an increase of the concentration of some indole compounds. The compounds found in the tested biomass from in vitro culture on Oddoux medium without and with addition of L-tryptophan were L-tryptophan, 5-hydroxy-L-tryptophan, serotonin, melatonin, tryptamine, and 5-methyltryptamine (ranged from 4.28 to $132.51 \mathrm{mg} / 100 \mathrm{~g}$ dry weight). L-Tryptophan is an amino acid exogenous to the human body, and therefore, it must be supplied to the body with food. The highest amount of 5-hydroxy-L-tryptophan was found in the extracts from biomass of $B$. badius cultured on medium with addition of L-tryptophan $(132.51 \mathrm{mg} / 100 \mathrm{~g}$ dry weight). Also, in this case, the highest total content of examined indole compounds (168.00 mg/100 g dry weight) was determined. Melatonin was found only in biomass of A. bisporus cultured on medium with addition of L-tryptophan but in smaller amount $(4.28 \mathrm{mg} / 100 \mathrm{~g}$ dry weight).

Key Words: Agaricus bisporus, Boletus badius, Cantharellus cibarius, indole compounds, 5-hydroxy-L-tryptophan; TLC analysis with densitometric detection

\section{Introduction}

Wide variety of mushroom species, their morphological diversity, and rich chemical composition had drawn the attention of scientists searching the environment for new biologically active compounds. The search resulted in finding in numerous mushroom species dietetic, anticancer, neuroprotective, antimicrobial, immunostimulating, and many other substances usable in civilization diseases treatment [1-4]. 
Compounds that have indole ring in their structure such as L-tryptophan, serotonin, or melatonin act as neurotransmitters in organism. They are responsible for the day and night cycle regulation, mood, appetite, body temperature, and blood clotting. They also modulate immunological response and have an influence on cell regeneration. Indole compounds have also antioxidative properties - what reflects in their anticancer and anti-aging action [5].

It was proven that serotonin takes part in mood and appetite regulation - low concentration of serotonin is linked to depression and obesity. During clinical trials, it was shown that intravenous administration of serotonin precursor - 5-hydroxy-L-tryptophan (5-HTP) - increases leptin level in mice blood - a substance released from adipocytes that decreases the appetite. The effect of 5-hydroxy-L-tryptophan administration in this case gives hope for a new drug used in obesity [6]. Other research confirmed L-tryptophan efficacy in depression symptoms treatment on any depression level. 5-Hydroxy-L-tryptophan was well tolerated by patients, and the antidepressant effect was comparable to synthetic drug - fluoxetine [7]. Serotonin precursor is potentially better antidepressant agent than serotonin or L-tryptophan because its transport does not involve a carrier and can be administered orally (what does not decrease its efficacy). 5-HydroxyL-tryptophan penetrates brain-blood barrier, increasing not only serotonin but also dopamine and norepinephrine concentrations. This substance is successfully used in treatment of depression, insomnia, appetite disorders, and chronic headaches. The usage of 5-hydroxy-L-tryptophan (5-HTP) does not involve dangerous adverse effects - up till now, only nausea was observed in patients receiving 5-HTP; the effect can be countered by the initial low dose treatment and a gradual increase, depending on the patient's state [8]. There were also trials involving simultaneous 5-HTP and Carbidopa usage. Carbidopa lowers peripheral L-DOPA decomposition in Parkinson's disease patients, consequently increasing the therapy efficacy. Due to the fact that the same enzyme is responsible for 5-HTP metabolism to serotonin and conversion of L-DOPA to dopamine, simultaneous administration of Carbidopa and 5-HTP increased the plasma 5-HTP concentration 14-fold in comparison to monotherapy [9]. 5-HTP brings also a new hope for Parkinson's disease patients. People receiving L-DOPA for a prolonged period of time develop dyskinesia (involuntary, uncontrollable movements). Clinical trials showed that administration of L-DOPA with 5-HTP decreases this syndrome occurrence $[9,10]$.

In medicine, other indole derivatives such as indometacin, acemetacin, or sulindac are used as potent anti-inflammatory and pain relieving agents. 
In pharmacotherapy, also, chelates of indole compounds with metals (e.g., indometacin with copper ions) are used on purpose to decrease indomethacin side effects and multiply its pain relieving activity [11].

Kohlmünzer made the thin-layer chromatography (TLC) analysis of indole compounds in inedible mushrooms [12]. He reported the presence of L-tryptophan in mushroom under study. Since 2007, Muszyńska examined the content of this group of compounds by chromatographic methods: HPLC and TLC coupled with densitometric detection in edible mushrooms. The research conducted by Muszyńska confirmed the presence of indole compounds in fruiting bodies of Agaricus bisporus, Boletus badius, and Cantharellus cibarius species used in this research $[13,14]$. These species were chosen for preparation of in vitro cultures and research on accumulation of L-tryptophan derivatives because of their popularity among consumers and their health qualities $[15,16]$.

The aim of presented research is to find optimal conditions of extraction and determination of indole derivatives by TLC method coupled with densitometric detection for biomass of in vitro culture of chosen species of edible mushrooms such as A. bisporus, B. badius, and C. cibarius, to determine for the first time the connection of accumulation degree with L-tryptophan and to find the dependence of culture media composition on biomass growth, and its metabolites in comparison to the fruiting bodies of selected mushrooms. As far as we know, this kind of analysis for mushrooms material is done for the first time by us. The research for the optimal composition of the medium in the commercial cultivation of mushrooms, that would allow supplementation of fruiting bodies, is an innovative task. There is a strong possibility to transfer the obtained results on the basis of technologically fortified varieties of the selected elements and micronutrients. Mushrooms will also probably allow creation of an out of the counter (OTC) preparation, effective, for example, as an antioxidant and antidepressant in therapy.

All this can be made after performing certain research and implementations which are included in our project.

\section{Experimental}

\section{Reagents and Materials}

Methanol and ammonium acetate, both of HPLC grade, were from Merck (Darmstadt, Germany). Propan-2-ol, butan-1-ol, ethyl acetate, petroleum ether, and ammonia $25 \%$, all of analytical grade, were from Polish Company 
of Chemistry (Gliwice, Poland); acetic acid (Chempur, Piekary Śląskie) and hypochlorite sodium were manufactured by Unilever, Hungary. The standards, L-tryptophan, 5-hydroxy-L-tryptophan, 5-methyltryptamine, tryptamine, serotonin, and melatonin (all of HPLC grade) were from SigmaAldrich (St. Louis, Mo, USA). Water was purified by redistillation and filtered through a syringe-driven filter unit (Millex Millipore, Billerica, MA, USA). Standard solutions were prepared in methanol (HPLC grade).

The studies were conducted on young fruiting bodies of A. bisporus (white button mushroom) of commercial origin (supermarket in Poland). B. badius (Bay bolete) and C. cibarius (Chanterelle) were harvested from natural state in southern Poland (near Kraków 2011-2013). After taxonomic identification according to Knudsen and Vesterholt [17] (representative samples of mushrooms were deposited in the Department of Pharmaceutical Botany, Jagiellonian University Collegium Medicum, Kraków, Poland), some of young sporocarps were used to derive in vitro culture from which the mycelium for further analysis was obtained

\section{In Vitro Culture}

The pieces of fruiting bodies were defatted with $70 \%$ ethyl alcohol for $15 \mathrm{~s}$ then sterilized in $15 \%$ hypochlorite sodium. After being rinsed several times with sterile redistilled water, mycelium fragments were transferred to Petri dishes containing agar-solidified medium with composition according to Oddoux [18].

\section{Experimental in Vitro Culture}

After growing on solid medium, the pieces of mycelium were placed in an Erlenmeyer flask $(500 \mathrm{~mL}$ ) containing $250 \mathrm{~mL}$ of modified liquid Oddoux medium; the initial biomass amount was $0.1 \mathrm{~g}$. The cultures were shaken at a rate of $140 \mathrm{rpm}$ (shaker ALTEL, Łódź). Cultures were incubated at the temperature $25 \pm 2^{\circ} \mathrm{C}$ under $16 \mathrm{~h}$ light ( $900 \mathrm{~lx} / 8 \mathrm{~h}$ dark). The agitated liquid cultures of $A$. bisporus were maintained for 2 weeks and, after this time, subcultured.

The agitated liquid cultures of A. bisporus, B. badius, and C. cibarius on Oddoux medium with addition of L-tryptophan $(0.5 \mathrm{~g} / \mathrm{L})$ were maintained for 2 weeks. After 2 weeks, the biomass was separated from the liquid medium using a filter paper on Büchner funnel, rinsed with redistilled water. The obtained fresh biomass, mycelium from in vitro cultures of mushrooms 
(50 $\mathrm{g}$ of each species) and mycelium of the same species from in vitro cultures with additional L-tryptophan to medium (50 g), were frozen and immediately dried by lyophilization (lyophilizer Freezone 4.5. Labconco; temperature: $-40^{\circ} \mathrm{C}$ ) for quantitative analyses.

\section{Sample Preparation}

The lyophilized biomass of mushrooms was weighed ( $5 \mathrm{~g}$ of each species), ground in a mortar, and then subjected to extraction with petroleum ether in percolators in order to remove the lipid fraction according to the procedure developed by Muszyńska (2007) [19]. These oil fractions were discarded, and the remaining biomass was dried and again subjected to extraction with methanol in a percolator for $24 \mathrm{~h}$ (kept in the dark). The extracts were concentrated by distillation in a vacuum evaporator (Buchi, Germany) under reduced pressure $(200 \mathrm{mbar})$ at $40{ }^{\circ} \mathrm{C}$. To remove the remaining lipids, the concentrated extracts were frozen. Polysaccharides were removed using the Chihara method [20]. The residues were quantitatively dissolved in methanol, filtered through Whatman No. 3 paper and purified by TLC. For the purification of the extracts, TLC on aluminum-backed silica gel 60 plates was used (Merck, Darmstadt, Germany, Art. No. 1.055540001), onto which $2 \mathrm{~mL}$ of methanolic extracts was loaded. Ten plates were used for each sample. Chromatograms were developed in a mobile phase which was found to be optimal for the separation of indole compounds: $n$-propanolethyl acetate-water $(7: 1: 2 v / v / v)$. Spots containing indole compounds were identified under an ultraviolet (UV) lamp at $\lambda=254 \mathrm{~nm}$ and were checked by comparison of UV spectra with spectra UV of standard compounds. In the next steps, spots containing indole compounds were scrapped and washed with methanol. The obtained fractions were extracted from the chromatograms with methanol, filtered through a syringe-driven filter unit (Millex, Millipore Corporation, USA), and then concentrated by distillation in a vacuum evaporator under reduced pressure at $40{ }^{\circ} \mathrm{C}$. The extracts quantitatively dissolved in $1.5 \mathrm{~mL}$ of methanol were subjected to TLC analyses coupled with densitometric detection.

The statistical analyses were performed using Student's test. For each of mycelium from in vitro cultures and mushroom fruiting bodies, five samples were used for the determination of every compound, and all the analyses were carried out in three repetitions. The results were expressed as mean values and standard deviation (SD). All the analyses were conducted 
using Statistica 10 (StatSoft, Poland). Statistical significance was defined at $p<0.05$.

\section{TLC Analysis with Densitometric Detection}

TLC analyses with densitometric detection were performed on TLC on aluminum-backed silica gel 60 plates (Merck, Darmstadt, Germany, Art. No. 1.055540001) and were performed using an apparatus Camag (Muttenz, Switzerland) Linomat IV sample applicator and Camag TLC Scanner 3 densitometer with winCATS software. Solutions of standard substances, i.e., of the indole compounds (L-tryptophan, 5-hydroxy-L-tryptophan, melatonin, 5-methyltryptamine, and serotonine were from Sigma-Aldrich St. Louis, Mo, USA, all of HPLC grade) found in the extracts under study were prepared. The solutions were prepared by dissolving the substances in methanol at the following concentrations: 5-hydroxy-L-tryptophan: 0.560 $\mathrm{mg} \mathrm{mL}-1,0.112 \mathrm{mg} \mathrm{mL}^{-1}$; L-tryptophan: $0.560 \mathrm{mg} \mathrm{mL}^{-1}, 0.112 \mathrm{mg} \mathrm{mL}^{-1}$; melatonin: $0.500 \mathrm{mg} \mathrm{mL}^{-1}, 0.108 \mathrm{mg} \mathrm{mL}^{-1}$; 5-methyltryptamine: $0.440 \mathrm{mg} \mathrm{mL}^{-1}$, $0.038 \mathrm{mg} \mathrm{mL}^{-1}$; serotonin: $0.800 \mathrm{mg} \mathrm{mL}^{-1}, 0.049 \mathrm{mg} \mathrm{mL}^{-1}$.

The chosen mobile phases were composed of the following:

A: propan-2-ol-25\% $\mathrm{NH}_{3}$-water $(8: 1: 1 \mathrm{v} / \mathrm{v} / \mathrm{v})$

B: butan-1-ol-glacial acetic acid-water $(12: 3: 5 v / v / v)$

In the first step of the research, the conditions of analyzed substances separation were determined. With an application of one mobile phase, no satisfactory results were obtained. Usage of mixed mobile phase composed of propan-2-ol-25\% $\mathrm{NH}_{3}$-water $(8: 1: 1 \mathrm{v} / \mathrm{v} / \mathrm{v})$ (A) for serotonin and 5methyltryptamine separation yield better results, $R_{\mathrm{F}}=0.59$ for serotonin and $R_{\mathrm{F}}=0.71$ for 5 -methyltryptamine (Fig. 1).

5-Hydroxy-L-tryptophan $\left(R_{\mathrm{F}}=0.57\right)$, L-tryptophan $\left(R_{\mathrm{F}}=0.62\right)$, and melatonin $\left(R_{\mathrm{F}}=0.88\right)$ were determined on mobile phase (B) composed of butan-1-ol-glacial acetic acid-water (12:3:5 $v / v / v)$ (Fig. 2). Registration of stains of indole derivatives on chromatograms was done densitometrically at $\lambda=280 \mathrm{~nm}$ (Fig. 3).

A validation of TLC analyses with densitometric detection for determined indole compounds was carried. Accuracy, precision, linearity range, detection limit, and quantification limit were calculated. 


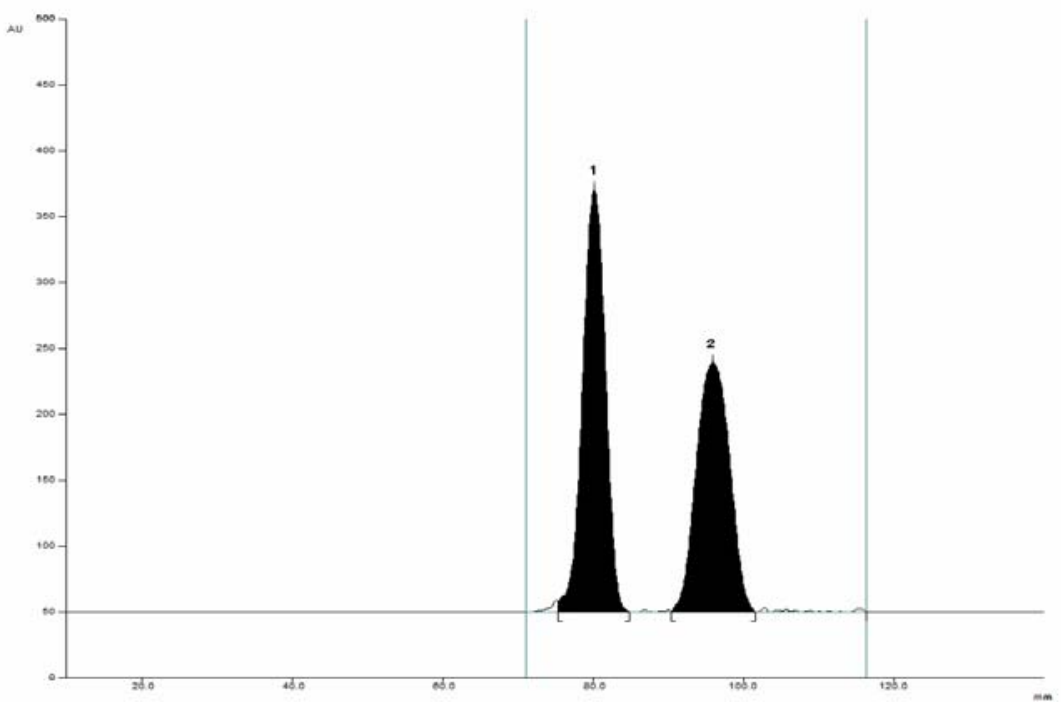

Fig. 1. Densitogram of serotonin (peak 1) and 5-methyltryptamine (peak 2) chromatographic separation on mobile phase (A):

propan-2-ol-25\% $\mathrm{NH}_{3}$-water $(8: 1: 1 \mathrm{v} / \mathrm{v} / \mathrm{v})$

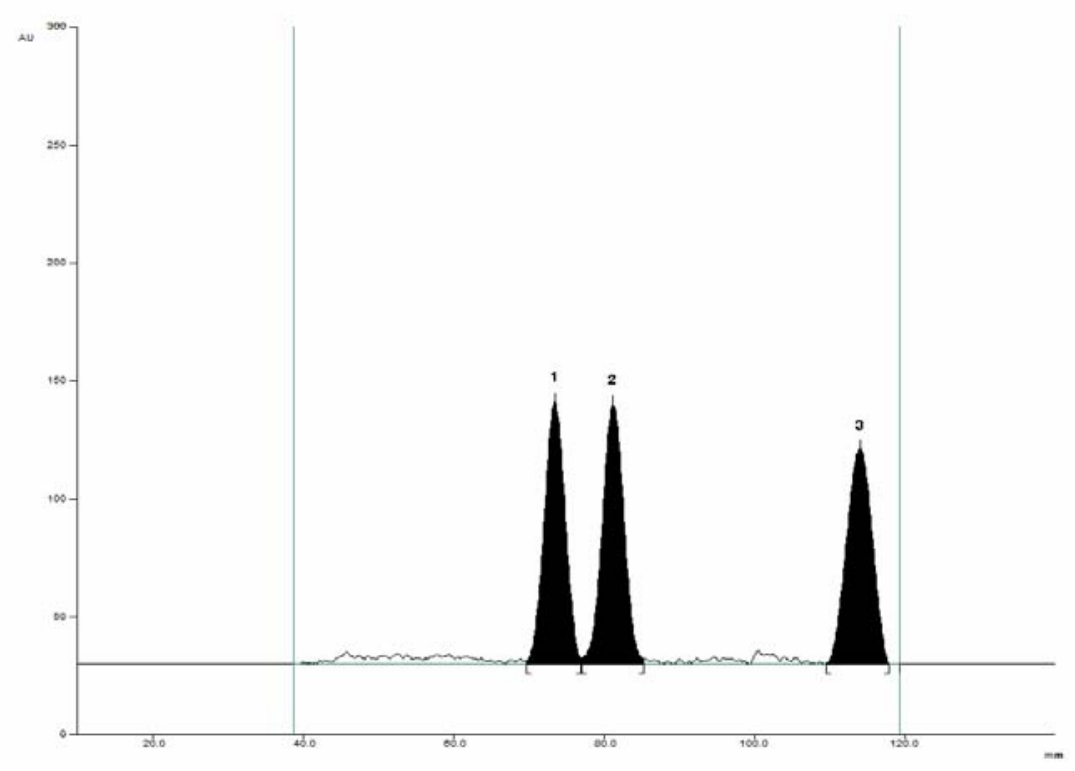

Fig. 2. Densitogram of 5-hydroxy-L-tryptophan (peak 1), L-tryptophan (peak 2) and melatonin (peak 3 ) chromatographic separation on mobile phase (B): butan-1-ol-glacial acetic acid-water $(12: 3: 5 v / v / v)$ 


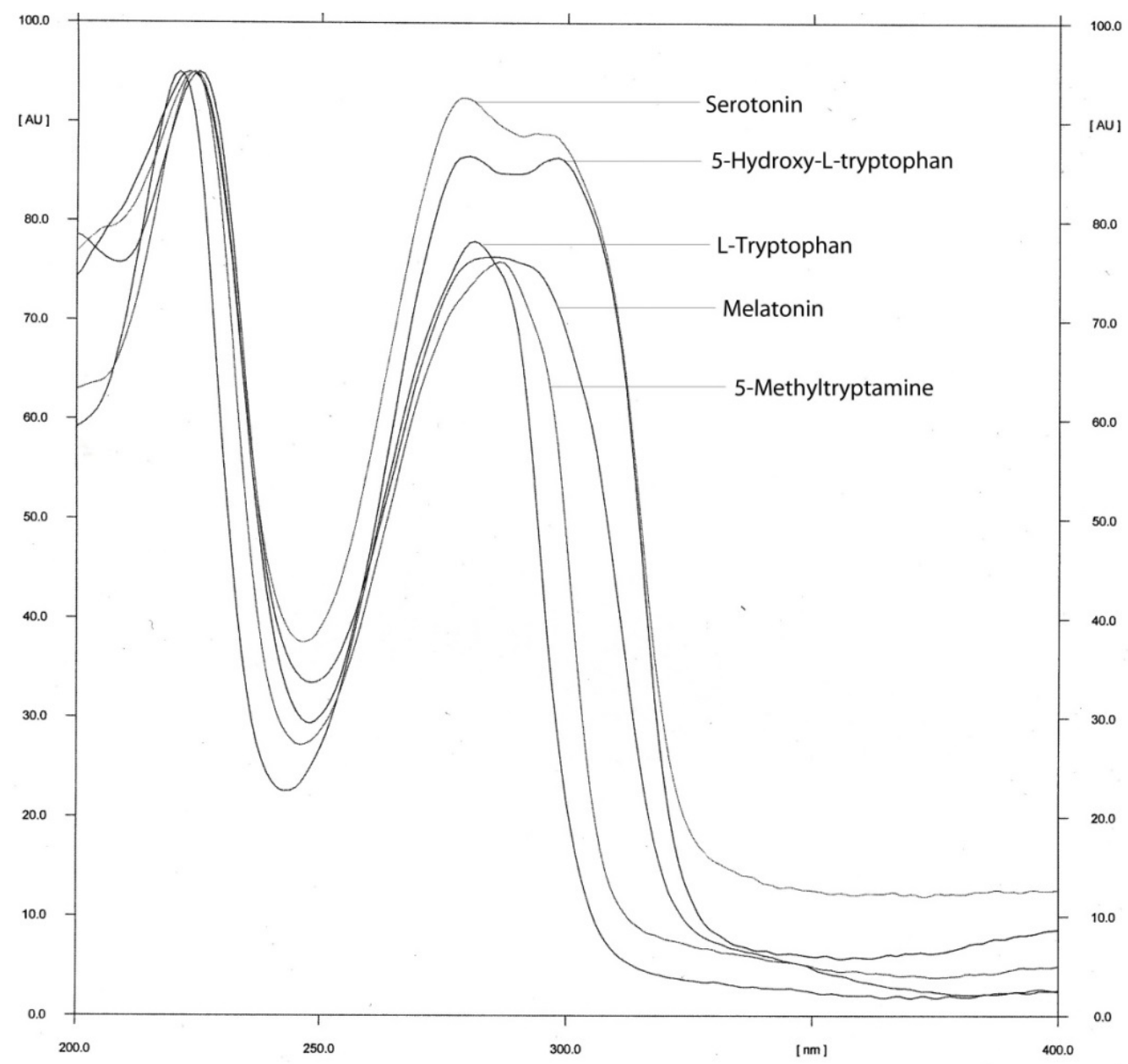

Fig. 3. Absorption spectra of studied indole compounds recorded directly from chromatograms

\section{Accuracy}

The accuracy of the method was assessed by calculating percent recovery for 5-methyltryptamine, serotonin, 5-hydroxy-L-tryptophan, L-tryptophan, and melatonin. The test was performed by the addition of an exactly known dose of the standard substance in the amount of from $80 \%$ to $120 \%$ of the declared 5-hydroxy-L-tryptophan, 5-methyltryptamine, L-tryptophan, and melatonin content. The determination was performed before and after the addition of the standard substance. 


\section{Precision}

Precision was estimated on solutions prepared for dissolving extracts from biomass of mushrooms under study in methanol. Determination was carried out five times for each sample (Table I).

Table I. Validation parameters for 5-hydroxy-L-tryptophan and 5-methyltryptamine determination

\begin{tabular}{|c|c|c|c|c|c|c|}
\hline Substance & $\begin{array}{c}R_{\mathrm{F}} \\
\text { (mobile } \\
\text { phase) }\end{array}$ & $\begin{array}{l}\text { Recovery } \\
(\%)\end{array}$ & $\begin{array}{l}\text { Precison } \\
\left(\mathrm{mm}^{2}\right)\end{array}$ & $\begin{array}{c}\text { LOD } \\
\left(\mu \mathrm{g} \mathrm{spot}^{-1}\right)\end{array}$ & $\begin{array}{c}\text { LOQ } \\
\left(\mu \mathrm{g} \mathrm{spot}^{-1}\right)\end{array}$ & Linear range \\
\hline $\begin{array}{l}\text { 5-Methyl } \\
\text { tryptamine }\end{array}$ & $\begin{array}{l}\sim 0.71 \\
(\mathrm{~A})\end{array}$ & $\begin{aligned} \bar{x} & =98.20 \\
S_{\mathrm{x}} & =2.51 \\
\mathrm{RSD} & =2.56 \%\end{aligned}$ & $\begin{array}{c}\bar{x}=5195.2 \\
S_{\mathrm{x}}=66.15 \\
\mathrm{RSD}=1.27 \% \\
\end{array}$ & $\begin{array}{c}0.040 \\
a=7296.3 \\
S_{\mathrm{y}}=89.16\end{array}$ & 0.122 & $\begin{array}{c}p=7368.9 \cdot m-39.5 \\
r=0.99785\end{array}$ \\
\hline Serotonin & $\begin{array}{l}\sim 0.59 \\
(\mathrm{~A})\end{array}$ & $\begin{array}{c}\bar{x}=96.10 \\
S_{\mathrm{x}}=0.930 \\
\mathrm{RSD}=0.97 \%\end{array}$ & $\begin{array}{c}\bar{x}=5776.7 \\
S_{\mathrm{x}}=64.33 \\
\mathrm{RSD}=1.11 \%\end{array}$ & $\begin{array}{c}0.017 \\
a=6556.4 \\
S_{\mathrm{y}}=33.48\end{array}$ & 0.051 & $\begin{array}{c}p=5352.2 \cdot m+483.8 \\
r=0.99833\end{array}$ \\
\hline $\begin{array}{l}\text { 5-Hydroxy- } \\
\text { L- } \\
\text { tryptophan }\end{array}$ & $\begin{aligned} \sim & 0.57 \\
& (\mathrm{~B})\end{aligned}$ & $\begin{array}{c}\bar{x}=97.45 \\
S_{\mathrm{x}}=0.762 \\
\mathrm{RSD}=0.78 \%\end{array}$ & $\begin{aligned} & \bar{x}=5398.5 \\
& S_{\mathrm{x}}=82.94 \\
& \mathrm{RSD}=1.54 \% \\
&\end{aligned}$ & $\begin{array}{c}0.079 \\
a=2668.7 \\
S_{\mathrm{y}}=63.70\end{array}$ & 0.239 & $\begin{array}{c}p=2587.1 \cdot m-128.7 \\
r=0.99918\end{array}$ \\
\hline $\begin{array}{l}\text { L- } \\
\text { Tryptophan }\end{array}$ & $\begin{array}{l}\sim 0.62 \\
(\mathrm{~B})\end{array}$ & $\begin{aligned} \bar{x} & =97.65 \\
S_{\mathrm{x}} & =2.01 \\
\mathrm{RSD} & =2.06 \%\end{aligned}$ & $\begin{aligned} \bar{x} & =4357.5 \\
S_{\mathrm{x}} & =82.98 \\
\mathrm{RSD} & =1.90 \%\end{aligned}$ & $\begin{array}{c}0.086 \\
a=2451.1 \\
S_{\mathrm{y}}=63.24\end{array}$ & 0.258 & $\begin{array}{c}p=2182.0 \cdot m+299.6 \\
r=0.99764\end{array}$ \\
\hline Melatonin & $\begin{array}{l}\sim 0.88 \\
\text { (B) }\end{array}$ & $\begin{array}{c}\bar{x}=100.11 \\
S_{\mathrm{x}}=2.238 \\
\mathrm{RSD}=2.23 \%\end{array}$ & $\begin{array}{c}\bar{x}=1160.6 \\
S_{x}=30.23 \\
\text { RSD }=2.60 \%\end{array}$ & $\begin{array}{c}0.145 \\
a=4017.8 \\
S_{\mathrm{y}}=176.34\end{array}$ & 0.439 & $\begin{array}{c}p=3565.5 \cdot m+346.4 \\
r=0.99584\end{array}$ \\
\hline
\end{tabular}

$\bar{x}$ - mean value for $n=5, S_{\mathrm{x}}$ - standard deviation, RSD - relative standard deviation, $p$ - area under peak $\left(\mathrm{mm}^{2}\right), m$ - substance mass used $\left(\mu \mathrm{g}\right.$ spot $\left.^{-1}\right)$, $S_{\mathrm{y}}-$ standard estimation error, $r$ - linear correlation coefficient, $a-$ slope

\section{Linear range}

Linear range was estimated as dependence of area under peak $\left(p\left[\mathrm{~mm}^{2}\right]\right)$ on the amount of substance used $\left(\mu \mathrm{g} \mathrm{spot}^{-1}\right)$, in concentration range between $0.038 \mu \mathrm{g}$ spot $^{-1}$ and $0.646 \mu \mathrm{g}$ spot $^{-1}$ for 5-methyltryptamine from 0.050 $\mu \mathrm{g}$ spot $^{-1}$ to $1.590 \mu \mathrm{g}$ spot $^{-1}$ for serotonin, from $0.112 \mu \mathrm{g} \mathrm{spot}{ }^{-1}$ to 2.464 $\mu \mathrm{g}$ spot $^{-1}$ for 5-hydroxy-L-tryptophan, from $0.112 \mu \mathrm{g}$ spot $^{-1}$ to 3.136 $\mu \mathrm{g} \mathrm{spot}{ }^{-1}$ for L-tryptophan, and from $0.109 \mu \mathrm{g} \mathrm{spot}^{-1}$ to $1.737 \mu \mathrm{g} \mathrm{spot}^{-1}$ for melatonin. Linear range of determined compounds was shown as equations describing the curves and linear correlation coefficient values $(r)$. 


\section{Limit of detection (LOD) and limit of quantification (LOQ)}

Detection limit and quantification limit were determined basing upon linear ranges from $0.038 \mu \mathrm{g} \mathrm{spot}^{-1}$ to $0.304 \mu \mathrm{g} \mathrm{spot}^{-1}$ for 5-methyltryptamine, from $0.050 \mu \mathrm{g} \mathrm{spot}^{-1}$ to $0.397 \mu \mathrm{g} \mathrm{spot}^{-1}$ for serotonin, from $0.112 \mu \mathrm{g} \mathrm{spot}^{-1}$ to 1.792 $\mu \mathrm{g}$ spot $^{-1}$ for 5-hydroxy-L-tryptophan, from $0.112 \mu \mathrm{g}$ spot $^{-1}$ to 1.792 $\mu \mathrm{g} \mathrm{spot}{ }^{-1}$ for L-tryptophan, and from $0.109 \mu \mathrm{g} \mathrm{spot}{ }^{-1}$ to $0.869 \mu \mathrm{g} \mathrm{spot}^{-1}$ for melatonin. LOD and LOQ were calculated with formulae LOD $=3.3 S_{\mathrm{y}} / a$, $\mathrm{LOQ}=10 S_{\mathrm{y}} / a$, in which $S_{\mathrm{y}}$ is standard estimation error and $a$ is slope (Table I).

During the research, the procedure of analysis was determined.

\section{Substances determination}

On $10 \mathrm{~cm} \times 14 \mathrm{~cm}$ TLC plates, reference solution and samples were added as a line of $1 \mathrm{~cm}$ length, $3 \mu \mathrm{L}$ of reference solution, and $4 \mu \mathrm{L}$ of sample (quintuple diluted in methanol if needed). Chromatograms were developed up to $13.5 \mathrm{~cm}$, in a chromatographic chamber saturated with mobile phase A,

Table II. Contents of the indole compounds in extracts from biomass of mushrooms $(\mathrm{mg} / 100 \mathrm{~g} \mathrm{DW})$

\begin{tabular}{|c|c|c|c|c|c|}
\hline Sample & $\begin{array}{c}5- \\
\begin{array}{c}\text { Methyltryptamine } \\
(\mathrm{mg} / 100 \mathrm{~g})\end{array} \\
\end{array}$ & $\begin{array}{l}\text { Serotonin } \\
(\mathrm{mg} / 100 \mathrm{~g})\end{array}$ & $\begin{array}{l}\text { 5-Hydroxy-L- } \\
\text { tryptophan } \\
(\mathrm{mg} / 100 \mathrm{~g})\end{array}$ & $\begin{array}{l}\text { L-Tryptophan } \\
\text { (mg/100g) }\end{array}$ & $\begin{array}{l}\text { Melatonin } \\
(\mathrm{mg} / 100 \mathrm{~g})\end{array}$ \\
\hline $\begin{array}{l}\text { Agaricus bis- } \\
\text { porus }\end{array}$ & $\begin{aligned} \bar{x} & =22.53 \\
S_{\mathrm{x}} & =0.199 \\
\mathrm{RSD} & =0.88 \%\end{aligned}$ & $\begin{array}{c}\bar{x}=7.05 \\
S_{\mathrm{x}}=0.160 \\
\mathrm{RSD}=2.27 \%\end{array}$ & $\begin{aligned} \bar{x} & =16.94 \\
S_{\mathrm{x}} & =0.194 \\
\mathrm{RSD} & =1.14 \%\end{aligned}$ & $\begin{array}{c}\bar{x}=14.23 \\
S_{\mathrm{x}}=0.268 \\
\operatorname{RSD}=1.88 \%\end{array}$ & - \\
\hline $\begin{array}{l}\text { Agaricus bis- } \\
\text { porus + L- } \\
\text { tryptophan }\end{array}$ & $\begin{array}{c}\bar{x}=18.92 \\
S_{\mathrm{x}}=0.130 \\
\mathrm{RSD}=0.69 \%\end{array}$ & $\begin{array}{c}\bar{x}=13.72 \\
S_{\mathrm{x}}=0.380 \\
\mathrm{RSD}=2.77 \%\end{array}$ & $\begin{array}{c}\bar{x}=9.93 \\
S_{\mathrm{x}}=0.261 \\
\mathrm{RSD}=2.63 \%\end{array}$ & $\begin{array}{c}\bar{x}=10.66 \\
S_{\mathrm{x}}=0.278 \\
\mathrm{RSD}=2.60 \%\end{array}$ & $\begin{array}{c}\bar{x}=4.34 \\
S_{\mathrm{x}}=0.088 \\
\text { RSD }=2.03 \% \\
\end{array}$ \\
\hline $\begin{array}{c}\text { Cantharellus } \\
\text { cibarius }\end{array}$ & - & $\begin{aligned} \bar{x} & =27.09 \\
S_{\mathrm{x}} & =0.380 \\
\mathrm{RSD} & =1.40 \%\end{aligned}$ & $\begin{aligned} \bar{x} & =33.32 \\
S_{\mathrm{x}} & =0.640 \\
\mathrm{RSD} & =1.92 \%\end{aligned}$ & $\begin{aligned} \bar{x} & =43.89 \\
S_{\mathrm{x}} & =0.830 \\
\mathrm{RSD} & =1.89 \%\end{aligned}$ & - \\
\hline $\begin{array}{l}\text { Cantharellus } \\
\text { cibarius + L- } \\
\text { tryptophan }\end{array}$ & $\begin{array}{c}\bar{x}=43.93 \\
S_{\mathrm{x}}=0.327 \\
\mathrm{RSD}=0.74 \%\end{array}$ & $\begin{array}{c}\bar{x}=9.27 \\
S_{\mathrm{x}}=0.183 \\
\mathrm{RSD}=1.98 \%\end{array}$ & $\begin{aligned} \bar{x} & =50.82 \\
S_{\mathrm{x}} & =0.712 \\
\mathrm{RSD} & =1.40 \%\end{aligned}$ & $\begin{aligned} \bar{x} & =19.16 \\
S_{\mathrm{x}} & =0.640 \\
\mathrm{RSD} & =3.34 \%\end{aligned}$ & - \\
\hline $\begin{array}{l}\text { Boletus } \\
\text { badius }\end{array}$ & $\begin{array}{c}\bar{x}=17.21 \\
S_{\mathrm{x}}=0.312 \\
\mathrm{RSD}=1.81 \%\end{array}$ & $\begin{array}{c}\bar{x}=29.80 \\
S_{\mathrm{x}}=0.351 \\
\mathrm{RSD}=1.78 \%\end{array}$ & $\begin{array}{c}\bar{x}=8.79 \\
S_{\mathrm{x}}=0.267 \\
\text { RSD }=3.04 \%\end{array}$ & $\begin{array}{c}\bar{x}=28.27 \\
S_{\mathrm{x}}=0.785 \\
\text { RSD }=2.77 \%\end{array}$ & - \\
\hline $\begin{array}{c}\text { Boletus } \\
\text { badius }+ \text { L- } \\
\text { tryptophan }\end{array}$ & $\begin{array}{c}\bar{x}=6.90 \\
S_{\mathrm{x}}=0.205 \\
\mathrm{RSD}=2.98 \%\end{array}$ & $\begin{array}{c}\bar{x}=132.51 \\
S_{\mathrm{x}}=3.116 \\
\mathrm{RSD}=2.35 \%\end{array}$ & $\begin{array}{c}\bar{x}=8.84 \\
S_{\mathrm{x}}=0.278 \\
\mathrm{RSD}=3.14 \%\end{array}$ & $\begin{array}{c}\bar{x}=19.75 \\
S_{\mathrm{x}}=0.384 \\
\text { RSD }=1.95 \%\end{array}$ & - \\
\hline
\end{tabular}

$\bar{x}-$ mean value for $n=5, S_{\mathrm{x}}-$ standard deviation, RSD - relative standard deviation 
which were used for determination of 5-methyltryptamine and serotonin and mobile phase $\mathrm{B}$ for determination of 5-hydroxy-L-tryptophan, L-tryptophan, and melatonin. Next, the plates were dried at room temperature. Densitometric registration was made at $280 \mathrm{~nm}$ wavelength.

Identification of indole compounds in the samples was performed with using internal standards. Compounds were identified basing on $R_{\mathrm{F}}$ for stains of extracts under study from reference and samples. The quantification was done by comparison of area under peak and then recalculated for $100 \mathrm{~g}$ of lyophilized sample. Results obtained for examined substances are shown in Table II.

\section{Results and Discussion}

Conditions developed during the experiments for determination of extract components by thin-layer chromatography with densitometric detection at UV light range allow identification and simultaneous determination of 5-hydroxy-L-tryptophan, L-tryptophan, melatonin, serotonin, and 5-methyltryptamine in biological material. Both qualitative and quantitative analysis is possible for analysed substances, after an initial separation, according to developed procedure which is followed by extraction and purification of the extract by semi-preparative thin-layer chromatography

Analysis of the compounds found in examined extracts was done on two mobile phases. Phase A: propan-2-ol-25\% $\mathrm{NH}_{3}$-water $(8: 1: 1 \mathrm{v} / \mathrm{v} / \mathrm{v})$ allowed separation of serotonin and 5-methyltryptamine, what showed on standard solutions (Fig. 1).

Differences in retention factors are considerable, which simplifies the identification of each component.

Densitometric analysis at $\lambda=280 \mathrm{~nm}$ allowed peak registration directly from well-developed chromatograms and ease of quantitative analysis (Fig. 1).

5-Hydroxy-L-tryptophan, L-tryptophan, and melatonin were determined on mobile phase composed of butan-1-ol-glacial acetic acid-water $(12: 3: 5 v / v / v)$, with densitometric detection at $\lambda=280 \mathrm{~nm}$ (Fig. 2).

Validation parameters gathered in Table I show that our methods have high sensitivity; LODs are $0.040 \mu \mathrm{g}$ for 5 -methyltryptamine, $0.017 \mu \mathrm{g}$ for serotonin, $0.079 \mu \mathrm{g}$ for 5-hydroxy-L-tryptophan, $0.086 \mu \mathrm{g}$ for L-tryptophan, and $0.145 \mu \mathrm{g}$ for melatonin. LOQs for all the compounds are $0.122 \mu \mathrm{g}$, $0.051 \mu \mathrm{g}, 0.239 \mu \mathrm{g}, 0.258 \mu \mathrm{g}$, and $0.439 \mu \mathrm{g}$, respectively. 
Recoveries for examined compounds were 98.20\%, 96.10\%, 97.45\%, $97.65 \%$, and $100.11 \%$. The described method is also characterized by high precision; relative standard deviations (RSDs) for determined compounds were $1.27 \%, 1.11 \%, 1.54 \%, 1.90 \%$, and $2.60 \%$.

Linearity for examined compounds is retained in wide range of concentrations: from $0.038 \mu \mathrm{g} \mathrm{spot}^{-1}$ to $0.646 \mu \mathrm{g} \mathrm{spot}^{-1}$ for 5-methyltryptamine, from $0.050 \mu \mathrm{g} \mathrm{spot}^{-1}$ to $1.590 \mu \mathrm{g} \mathrm{spot}^{-1}$ for serotonin, from $0.112 \mu \mathrm{g} \mathrm{spot}^{-1}$ to $2.464 \mu \mathrm{g} \mathrm{spot}{ }^{-1}$ for 5-hydroxy-L-tryptophan, from $0.112 \mu \mathrm{g} \mathrm{spot}^{-1}$ to 3.136 $\mu \mathrm{g} \mathrm{spot}{ }^{-1}$ for L-tryptophan, and from $0.109 \mu \mathrm{g} \mathrm{spot}^{-1}$ to $1.737 \mu \mathrm{g} \mathrm{spot}{ }^{-1}$ for melatonin.

Application of chromatographic method with densitometric detection for extracts analysis allows precise, reasonable determination of examined compounds.

It was determined that the most favorable conditions for mycelial growth are Oddoux (1957) medium, in temperature $25 \pm 2{ }^{\circ} \mathrm{C}$, lighting $900 \mathrm{~lx}$ for $16 \mathrm{~h}$ and $8 \mathrm{~h}$ in the dark, which substitutes natural day-night conditions. Forty-fold increases in biomass growth were obtained on liquid medium in 21-day growth cycles. Optimal initial $\mathrm{pH}$ value of the medium was 6.0. In these conditions after 3 weeks of incubation, a growth of $8 \mathrm{~g}$ of dry weight per a liter of medium was obtained. Optimal growth was obtained in liquid agitated medium.

The analyses demonstrated that all tested biomass of $A$. bisporus, $B$. badius, and C. cibarius contain non-hallucinogenic indole compounds (Figs. 4 and 5). Addition of L-tryptophan to the in vitro cultures raised the total content of indole compounds. L-Tryptophan was metabolized, causing a concentration increase of some indole compounds. The compounds found in the tested biomass from in vitro culture on Oddoux medium without and with addition of L-tryptophan were L-tryptophan, 5-hydroxy-L-tryptophan, serotonin, melatonin, tryptamine, and 5-methyltryptamine (ranging from 4.28 to $132.51 \mathrm{mg} / 100 \mathrm{~g}$ dry weight (DW)) (Table II). L-Tryptophan is an exogenous amino acid to the human organism, and therefore, it must be supplied with food. The highest amount of 5-hydroxy-L-tryptophan was determined in the extracts from biomass of $B$. badius cultured on medium with addition of L-tryptophan $(132.51 \mathrm{mg} / 100 \mathrm{~g} \mathrm{DW})$. In this case, also, the highest total content of examined indole compounds $(168.00 \mathrm{mg} / 100 \mathrm{~g}$ DW) was determined. Melatonin was estimated only in biomass of $A$. bisporus cultured on medium with addition of L-tryptophan but in the smallest amount (4.28 mg/100 g DW). L-Tryptophan, 5-hydroxy-L-tryptophan, and serotonin were detected in each material. It can be suggested that in vitro culture of edible mushrooms can be a valuable dietary source of physiologically active 


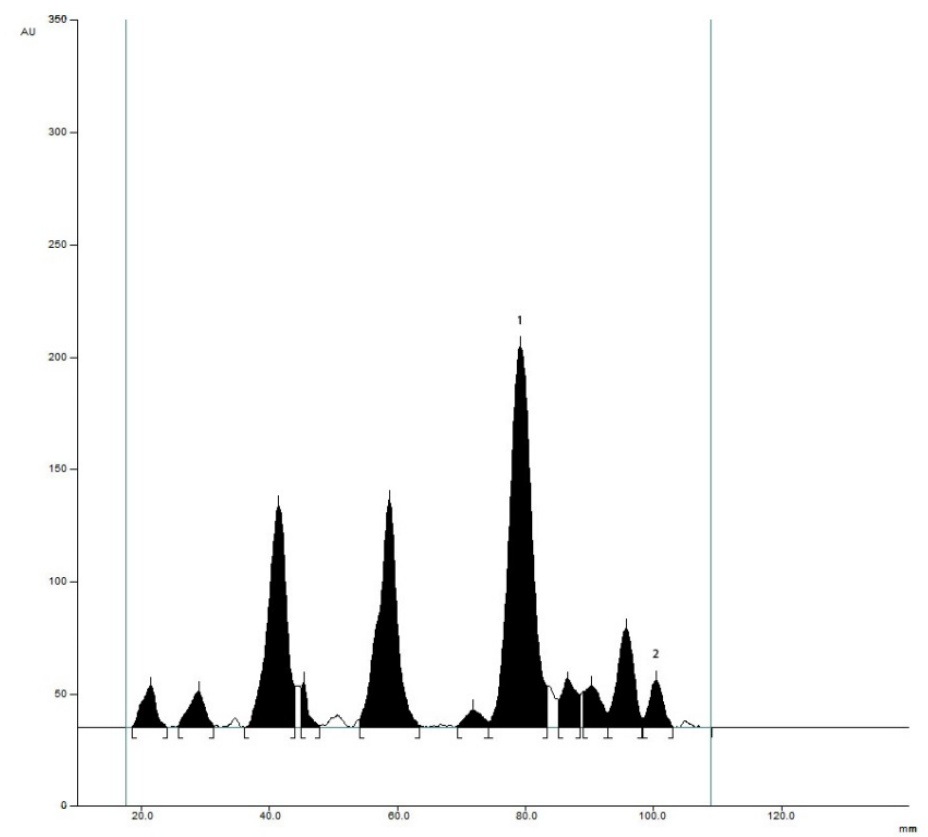

Fig. 4. Densitogram of Boletus badius biomass from in vitro culture with addition of L-tryptophan: serotonin (peak 1) and 5-methyltryptamine (peak 2), chromatographic separation on mobile phase (A): propan-2-ol-25\% $\mathrm{NH}_{3}$-water $(8: 1: 1 v / v / v)$

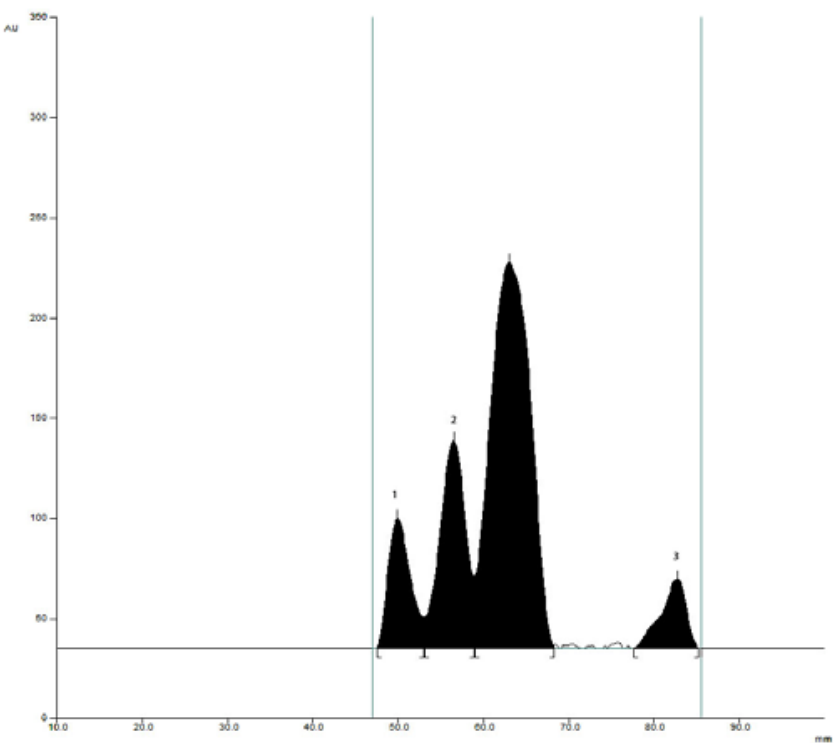

Fig. 5. Densitogram of Agaricus bisporus biomass from in vitro culture with addition of L-tryptophan (peak 1), L-tryptophan (peak 2), and melatonin (peak 3) chromatographic separation on mobile phase (B): butan-1-ol-glacial acetic acid-water (12:3:5 $v / v / v)$ 


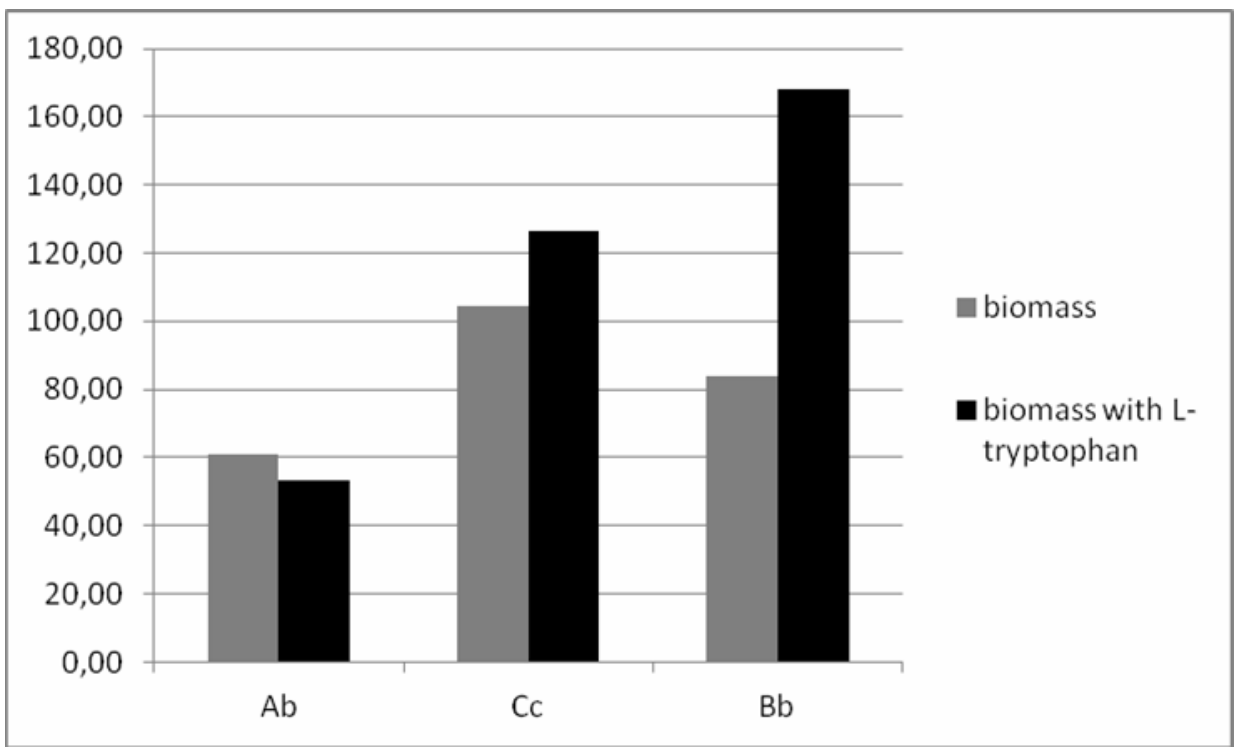

Fig. 6. The total contents of indole compounds in biomass from in vitro culture of mushrooms under study ( $\mathrm{Ab}-$ Agaricus bisporus, $\mathrm{Cc}-$ Cantharellus cibarius, $\mathrm{Bb}-$ Boletus badius)

indole compounds. It should be taken into account that serotonin does not cross the blood-brain barrier, while L-tryptophan and 5-hydroxy-Ltryptophan have this ability and, while being precursors of serotonin, have an antidepressant effect [21]. L-Tryptophan is a substrate for dopamine, melatonin, and adrenaline synthesis as well as for vitamins (niacin). Results of indole compounds quantity in in vitro cultures are considerably higher than previously obtained by Muszyńska in fruiting bodies [13, 14]. Maximum total amount of indole compounds in fruiting bodies was found in C. cibarius fruiting bodies and amounted $34.59 \mathrm{mg} / 100 \mathrm{~g}$ DW [22]. In methanolic extracts from the biomass of this species, total amount of indole compounds was on $104.30 \mathrm{mg} / 100 \mathrm{~g}$ DW level and on medium enriched with L-tryptophan $123.18 \mathrm{mg} / 100 \mathrm{~g}$ DW. In case of B. badius, biomass contained $84.07 \mathrm{mg} / 100 \mathrm{~g} \mathrm{DW}$, but the concentration was over two times higher when it was cultivated on medium enriched with L-tryptophan $(168.00 \mathrm{mg} / 100 \mathrm{~g}$ DW). Although the concentrations in fruiting bodies of A. bisporus were small [23], the amount of indole compounds in mycelium was ten times higher than in fruiting bodies. This shows that in vitro cultures of edible mushrooms are a better source of indole compounds. There was no increase in the level of L-tryptophan in the biomass of the in vitro culture medium 
enriched with this indole compound due to its metabolism to serotonin or 5-hydroxy-L-tryptophan and melatonin, which showed significant increase in the content. Figure 6 presents the total content of indole compounds in biomass from culture of mushrooms under study, and it can be observed that wild growing mushrooms (B. badius and C. cibarius) from in vitro culture with an addition of L-tryptophan accumulated the indole compounds even to two times bigger amount.

\section{Conclusion}

Edible species of mushrooms may play an important role in diet, not only because of taste, but also dietary values. In closed laboratory conditions, it is easier to control the accumulation of metabolites. We have for the first time identified and quantified indole compounds in biomass from in vitro culture on Oddoux medium with addition of L-tryptophan of three species belonging to the most popular edible mushrooms. The herein proposed method of in vitro cultures proved that L-tryptophan is effectively taken up and accumulated in the mycelia. Biomass from in vitro culture has ability to accumulate this compound and is a very good source of L-tryptophan. The obtained results indicate that in vitro cultures can be a good model for the studies on accumulation and metabolism of the essential amino acids in mushrooms. The most effective species for accumulation L-tryptophan derivatives is $B$. badius. This suggests that the next step should be to estimate the release and bioavailability of indole compounds from in vitro cultured mycelia in in vitro and in vivo conditions.

\section{References}

A. [1] S.P. Wasser and A. Weis, Critical Rev., Immunol. 19, 65-69 (1999)

A, 19, 65-69 (1999)

[2] B.Z. Zaidman, M. Yassin, J. Mahajana, and S.P. Wasser, Appl. Microbiol. Biotechnol., 67, 453-468 (2005)

[3] P. Kalaĉ, Food Chem., 113, 9-169 (2009)

[4] L. Barros, T. Cruz, P. Baptista, L.M. Estevinho, and I.C.F.R. Ferreira, Food Chem. Toxicol., 46, 2742-2747 (2008)

[5] M. Elmastas et al., J. Food Comp. Anal., 20, 337-345 (2007)

[6] P. Jangid, P. Malik, P. Singh, M. Sharma, and A.D. Gulia, Asian J. Psychiatry, 6, 2934 (2013)

[7] M. Turek and E. Łodyga-Chruścińska, Food Chem., 72, 73-88 (2008)

[8] E.H. Turner, J.M. Loftis, and A.D. Blackweell, Pharmacol. Ther., 109, 325-338 (2006) 
[9] E. Tronci, C. Lisci, R. Stancampiano, C. Fidalgo, et al., Neurobiol. Dis., 60, 108-114 (2013)

[10] B. Muszyńska and K. Sułkowska-Ziaja, Food Chem., 132, 455-459 (2012)

[11] M. Turek and E. Łodyga-Chruścińska, Food Chem., 72, 73-88 (2008)

[12] S. Kohlmúnzer, J. Węgiel, B. Muszyńska, K. Sułkowska-Ziaja, and J. Gouillot, Herba Pol., 2, 99-103 (2000)

[13] B. Muszyńska, K. Sułkowska-Ziaja, and H. Ekiert, Food Chem., 125, 1306-1308 (2011)

[14] B. Muszyńska and K. Sułkowska-Ziaja, and H. Ekiert, J. Food Sci. Technol., 50, 1233-1237 (2013)

[15] A.C. Ruthes et al., Carbohyd. Polym., 87, 1620-1627 (2012)

[16] A. C. Ruthes et al., Carbohyd. Polym., 92, 184-191 (2013)

[17] H. Knudsen and J. Vesterholt, Funga Nordica: Agaricoid, Boletoid and Cyphelloid Genera, Nordsvamp, Copenhagen, 2008

[18] L. Oddoux (Ed), Recherches sur les Mycéliums Secondaires des Homobasidiés en Culture Pure, Imprimerie de Trevoux, Lyon, 1957

[19] B. Muszyńska, A. Maślanka, K. Sułkowska-Ziaja, and J. Krzek, J. Planar. Chromatogr.-Mod. TLC, 20, 55-58 (2007)

[20] G. Chihara, I Hamuro, Y. Madea, Y. Arai, and P. Fukukoka, Cancer Res., 30, 2276$81(1970)$

[21] T.C. Birdsall, Altern. Med. Rev., 3, 271-280 (1998)

[22] B. Muszyńska and K. Sułkowska-Ziaja, Processing and Impact on Active Components in Food, Kings College London, Elsevier 7, 55-61 (2014)

[23] B. Muszyńska, K. Sułkowska-Ziaja, and H. Ekiert, Int. J. Med. Mushrooms, 13, 449$454(2011)$ 